\title{
Groundwater aquifer detection using the electrical resistivity method at Ito Campus, Kyushu University (Fukuoka, Japan)
}

\author{
Shafiqullah Wahab ${ }^{1}$, Hakim Saibi ${ }^{2 *}$ (ID and Hideki Mizunaga ${ }^{1}$
}

\begin{abstract}
An electrical resistivity survey was carried out using the pole-pole configuration around the Sayanokami spring area in the northern part of Ito Campus (Kyushu University, Fukuoka, Japan) to study the groundwater aquifer and its electrical characteristics. A Code Division Multiple Transmission (CDMT) system was used. The CDMT system transmits 24 currents simultaneously and measures 24 potential responses with monitoring of actual current waveforms. The system can inject current from multiple electrodes into the underground environment simultaneously using different individual current waveforms. The two-dimensional (2-D) inversion results of the electrical resistivity data indicate three layers from top to bottom, as follows: (a) a thin layer with a thickness of $3 \mathrm{~m}$ and a low resistivity $(<50 \Omega \mathrm{m})$ representing topsoil; (b) a groundwater aquifer layer with an average resistivity between 50 and $170 \Omega \mathrm{m}$ and with a thickness ranging from 7 to $10 \mathrm{~m}$, and (c) a highly resistive bedrock layer with resistivities higher than $200 \Omega \mathrm{m}$ and occupying depths from $15 \mathrm{~m}$ to the base of the model.
\end{abstract}

Keywords: Aquifer, Electrical resistivity, 2D inversion, Groundwater, Japan

\section{Introduction}

Electrical resistivity methods are widely used for groundwater investigations (El-Qady and Ushijima 2001; Ghosh, 1971; Griffith and Rooney 1993; Loke et al. 2014; Telford et al. 1990). The electrical resistivity technique has many advantages: (i) its ease of use in the field; (ii) its ability to provide information on depths ranging from a few meters to hundreds of meters beneath the surface, and (iii) the availability of software for $2 \mathrm{D}$ and $3 \mathrm{D}$ interpretation. The electrical resistivity method can solve many hydrogeological issues, including (1) monitoring of industrial waste contamination or pollutants (Rockhold et al. 2020); (2) determination of the spatial extent of groundwater aquifers (Greggio et al. 2018); (3) estimation of hydraulic parameters of aquifers (De Clercq et al. 2020; Kazakis

\footnotetext{
*Correspondence: hakim.saibi@uaeu.ac.ae; saibi.hakim@gmail.com ${ }^{2}$ Department of Geology, College of Science, United Arab Emirates University, P.O. Box 15551, Al Ain, UAE

Full list of author information is available at the end of the article
}

et al. 2016); (4) monitoring of aquifer recharge ponds (Sendros et al. 2020), and (5) characterization of seawater intrusions for coastal groundwater aquifers (Galazoulas et al. 2015; Niculescu and Andrei 2021).

There are two geophysical methods used for studying the electrical resistivity characteristics of groundwater aquifers. Electromagnetic methods can be used for detecting shallow and deep groundwater aquifers (McNeill, 1990). However, this method requires expensive equipment and must avoid cultural and industrial noise and power lines. Electrical methods include many techniques and configurations (arrays), can be used in areas with noise such as our study area, and are the most commonly used techniques for hydrogeological investigations.

On February 8 and 9, 2016, we conducted a geophysical electrical survey in the northern part of the Ito campus of Kyushu University (Fukuoka Prefecture, Japan) (Fig. 1). The objective of this geophysical electrical survey was to study the groundwater aquifer and its electrical 

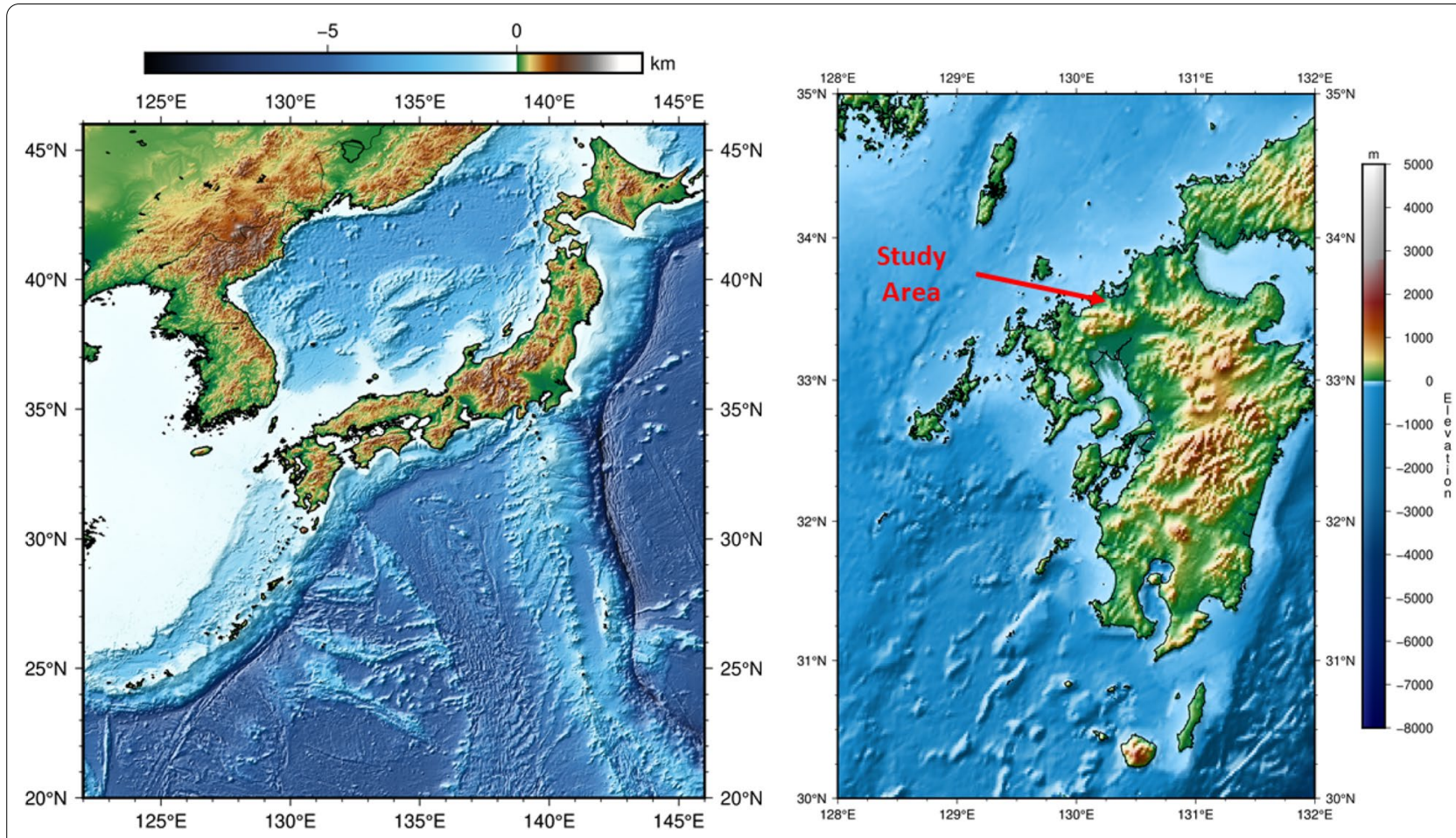

Fig. 1 Location of the study area in Japan

characteristics around the Sayanokami spring area on the Ito campus and to understand the resistivity structure and distribution beneath the study area. A further goal was to determine the depth and thickness of the aquifer and saturated zone for future possible well drilling for groundwater extraction.

\section{Outline of the survey area}

The study area is located in the northern part of the new Ito campus of Kyushu University (Fukuoka, Japan). The electrical survey was carried out in February 2016. The area is characterized by a forested cover and topsoil composed mainly of clay. Geologically, the study area mainly contains Quaternary alluvial rocks, Cretaceous granodiorites, and Paleozoic metamorphic rocks (Fig. 2a) (Yamaguchi et al. 1984). In this area, granodiorite is widespread. However, the resistivity surveys (Fig. 2b) were conducted where alluvium of Quaternary age is exposed. Topographically, the study area is quite flat.

\section{Methodology}

In this survey, we used the Code Division Multiple Transmission (CDMT) high-speed resistivity technique to infer the electrical resistivity distribution beneath the study area. The resistivity equipment consists of three parts: (1) the 24 channel amplifier $\left(T_{\mathrm{x}}\right),(2)$ the receiver $\left(R_{\mathrm{x}}\right)$, and (3) the power supply system (CMT 2019) (Fig. 3). To obtain the electrical resistivity values of the subsurface, we induced an electrical current in the ground through electrodes and measured the potentials (voltages) using other electrodes. From these electrical properties, we can infer the geological characteristics of the Earth's subsurface.

CDMT is an application of a multi-access communication technique used for mobile phone communication networks. The system can inject current from multiple electrodes underground simultaneously using different individual current waveforms. The covariance between each pair of current wave forms is exactly zero. Only simple processing is necessary to obtain a potential response for individual current electrodes. The system consists of a multi-channel voltage signal generator controlled by a personal computer (PC), a voltage to current converter using a constant current circuit, and a multi-channel A/D converter for voltage measurement. The maximum voltage for transmission is $\pm 100 \mathrm{~V}$, and the maximum current is $\pm 100 \mathrm{~mA}$.

The CDMT instrument is designed for a pole-pole configuration (Fig. 4). The pole-pole array is represented by one potential and one current electrode. The potential and current electrodes are located far from each other. The pole-pole array is known for its very high horizontal resolution and broad depth range.

The pole-pole configuration apparent resistivity formula is shown in Eq. (1) (Keller and Frischknecht 1996): 


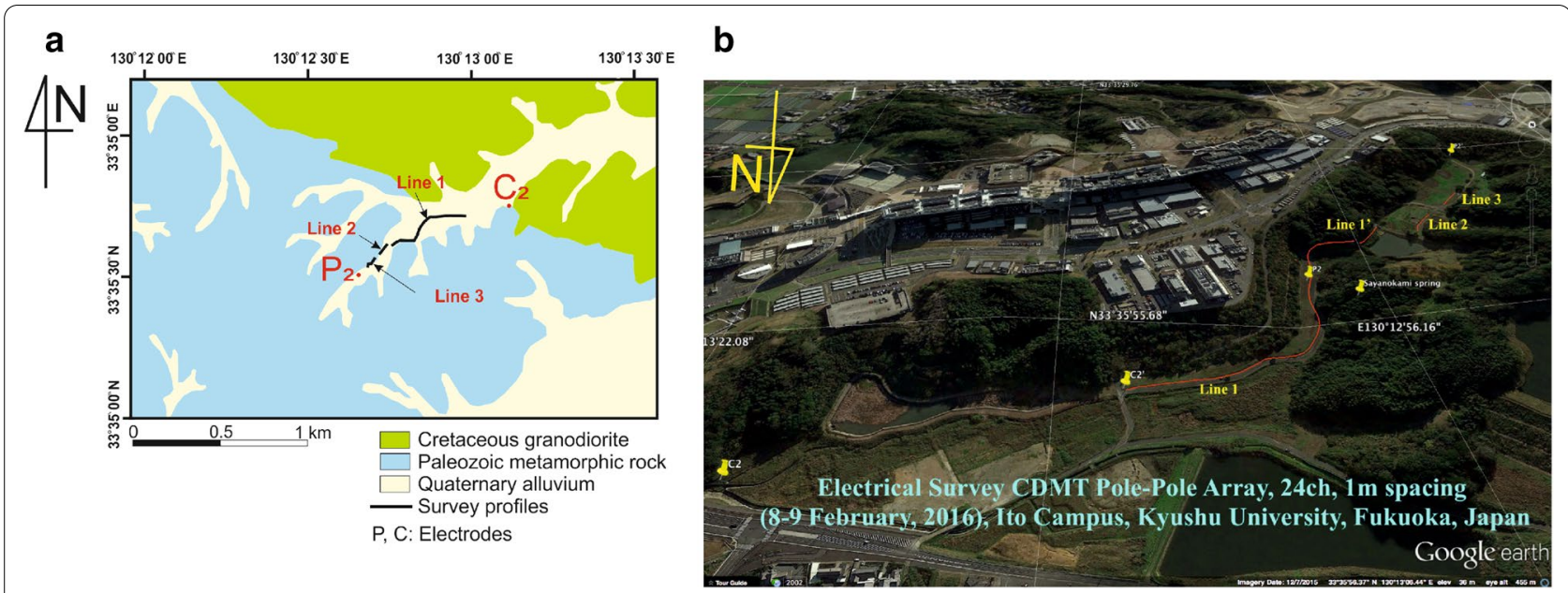

Fig. 2 a Geological map of the study area and locations of the electrical survey lines (Lines 1-3). b Google Earth map showing the locations of the electrical resistivity lines on the Ito campus (Kyushu University, Fukuoka, Japan)
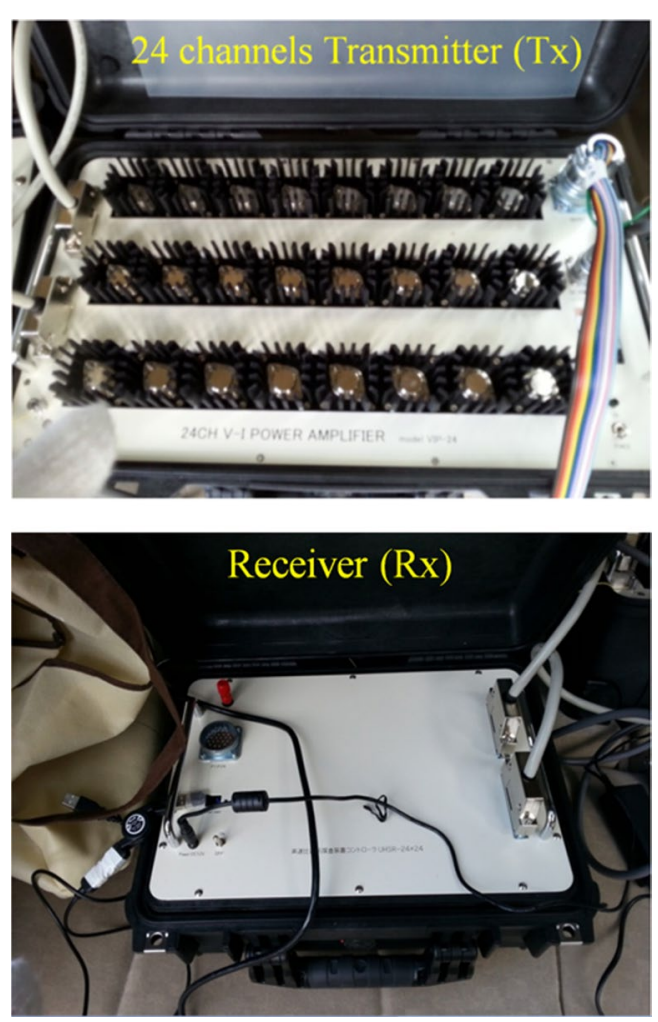

Fig. 3 Photos of the CDMT equipment (transmitter and receiver)

$$
\rho_{a}=\frac{V}{I}(2 \pi a)
$$

For groundwater investigation, we used Archie's law. Porous, water-bearing rocks or sediments may be ionic conductors in ground formations which are defined by Archie's law, presented in Eq. (2) (Archie 1942):

$$
\rho=a \emptyset^{-m} f^{-n} \rho_{w}
$$

where $\rho$ and $\rho_{w}$ are the resistivities of the rock and the water; $\phi$ is the porosity; $f$ is the volume fraction of pores containing water; $a, m$, and $n$ are empirical constants; and $0.5 \leq a \leq 2.5,1.3 \leq m \leq 2.5$, and $n$ is approximately 2 .

After all the data were recorded in the field, the data were inverted in order to obtain the apparent electrical resistivity distribution beneath the study area. Due to the nature of geophysical data, the geophysical model may have problems with hidden or suppressed layers, non-uniqueness, equivalence, and lack of resolution in parts of the model. The dependence of apparent resistivities on subsurface parameters is generally described as a nonlinear, differentiable forward mapping, stated as a linearized approximation by the first term of the Taylor series expansion (Auken and Christiansen 2004):

$$
\boldsymbol{d}_{o b s}=\boldsymbol{g}\left(\boldsymbol{m}_{r e f}\right)+\boldsymbol{G}\left(\boldsymbol{m}_{\text {true }}-\boldsymbol{m}_{r e f}\right)+\boldsymbol{e}_{o b s},
$$

where $\boldsymbol{g}$ is the nonlinear mapping of the model to the data space, and $\boldsymbol{d}_{o b s}$ is the observed data (apparent resistivities) with the corresponding error $\boldsymbol{e}_{o b s}$. The model vector, $\boldsymbol{m}$, contains layer resistivities and layer thicknesses in the $n$-layer 1-D case:

$$
\boldsymbol{m}=\left[\rho_{1}, T_{1}, \rho_{2}, T_{2}, \cdots, T_{n-1,} \rho_{n}\right]
$$

while for 2D smooth inversion, with a cell-based resistivity model, it contains the cell resistivities,

$$
\boldsymbol{m}=\left[\rho_{1}, \rho_{2}, \cdots, \rho_{n}\right] .
$$




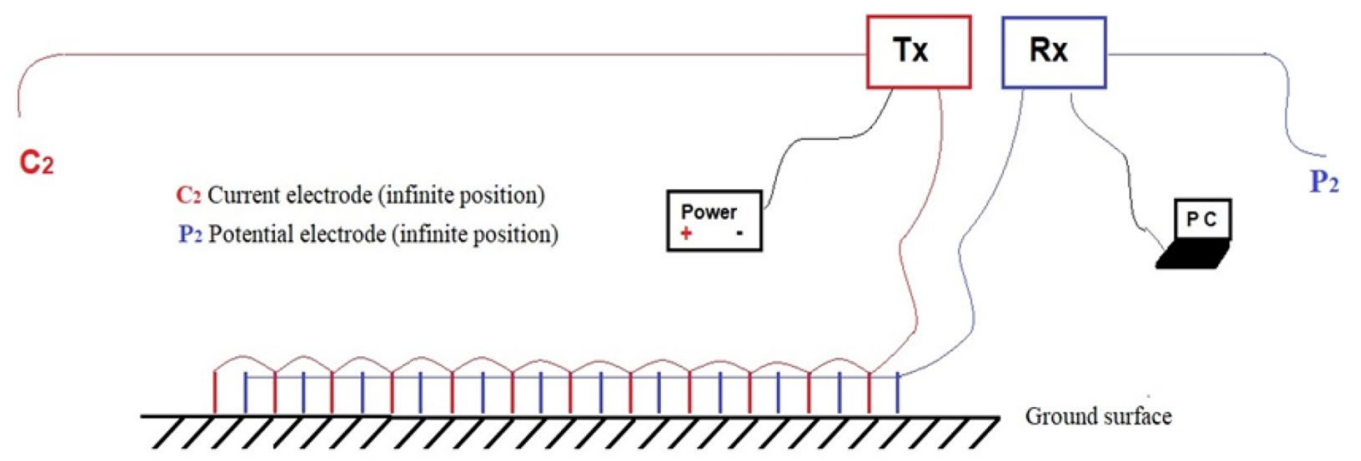

| Current electrode

I Potential electrode
Tx is the channel transmitter

$\mathbf{R x}$ is the receiver

$\mathrm{C}_{2}$ is current electrode (infinite position)

$\mathrm{P}_{2}$ is potential electrode (infinite position)

Fig. 4 A sketch showing the working concept of CDMT

The true resistivity model, $\boldsymbol{m}_{\text {true }}$, has to be sufficiently close to some arbitrary reference model $\mathrm{m}_{\text {ref }}$ for the linear approximation to be valid. The change of model parameters can be calculated by the following equation:

$$
\boldsymbol{G} \boldsymbol{\delta} \boldsymbol{m}_{\text {true }}=\boldsymbol{\delta} \boldsymbol{d}_{o b s}+\boldsymbol{e}_{o b s},
$$

where

$$
\delta \boldsymbol{d}_{o b s}=\left[\boldsymbol{d}_{o b s}-\boldsymbol{g}\left(\boldsymbol{m}_{r e f}\right)\right],
$$

and

$$
\delta \boldsymbol{m}_{\text {true }}=\boldsymbol{m}_{\text {true }}-\boldsymbol{m}_{\text {ref }} .
$$

The Jacobian, $\boldsymbol{G}$, contains the partial derivative of the residuals as follows (Auken and Christiansen 2004):

$$
\boldsymbol{G}_{s t}=\frac{\partial \boldsymbol{d}_{s}}{\partial \boldsymbol{m}_{t}}=\frac{\partial \log \boldsymbol{d}_{s}}{\partial \log \boldsymbol{m}_{t}}=\frac{\boldsymbol{m}_{t}}{\boldsymbol{d}_{s}} \frac{\partial \boldsymbol{d}_{s}}{\partial \boldsymbol{m}_{t}} .
$$

The logarithm ensures positivity of the data and the model parameters. One of the objectives of the resistivity inversion is to find a resistivity model whose response (predicted data) provides the best fit to the measured data. The goodness of the fit may be characterized by the root mean squares $(R M S)$ error in percent (\%), defined as follows:

$$
R M S=\sqrt{\frac{\sum_{i=1}^{N}\left(\frac{d_{i}^{\text {Pred }}-d_{i}^{\text {Meas }}}{d_{i}^{\text {Meas }}}\right)}{N}} \times 100,
$$

where $N$ is the total number of measurements, $d^{\text {Pred }}$ is the predicted data, and $d^{\text {Meas }}$ is the measured data. It is clear that the RMS error depends on the number of bad data points and their quality.

To construct a 3D inversion from resistivity data, we first need to calculate the forward solutions by solving this partial differential equation:

$$
\frac{\partial}{\partial_{x}}\left(\sigma \frac{\partial V}{\partial x}\right)+\frac{\partial}{\partial_{y}}\left(\sigma \frac{\partial V}{\partial y}\right)+\frac{\partial}{\partial_{z}}\left(\sigma \frac{\partial V}{\partial z}\right)=I(x, y, z),
$$

where $V$ is the scalar electric potential, and $I(x, y, z)$ is the electric current source term. The finite difference method with an elemental volume (Dey and Morrison 1979) was used to discretize the partial differential equation above. Dirichlet and mixed boundary conditions (Dey and Morrison 1979) were implemented. The matrix system was iteratively solved by a conjugate gradient (CG) method.

Geophysical inversion is known for its non-uniqueness. To address this problem, additional data and constraints should be employed to obtain an optimal model. Another solution requires developing a smooth inversion model. The objective function of the smooth inversion model is:

$$
\boldsymbol{S}(\boldsymbol{m})=\left(\boldsymbol{d}_{o b s}-g(\boldsymbol{m})\right)^{\mathrm{T}} \boldsymbol{W}_{d}\left(\boldsymbol{d}_{o b s}-g(\boldsymbol{m})\right)+a \cdot \boldsymbol{m}^{\mathrm{T}} \boldsymbol{R} \boldsymbol{m},
$$

where $a$ is a Lagrange multiplier and a smoothness factor. It determines the amount of model roughness imposed on the model during the inversion. $\mathrm{W}_{d}$ is a data weighting matrix, and $R$ is a roughness operator. The smoothness model inversion algorithm was originally described in Constable et al. (1987) and deGroot-Hedlin and Constable (1990). 


\section{Results}

The first stage in producing an electrical image is the construction of a pseudo-section. Each pseudo-section is a visual representation of unprocessed apparent resistivity values. It is useful to compare an inverted cross-section with the raw data to evaluate anomalies observed in the inversion. Figure 5 shows an example of a pseudo-section from Line 3. The pseudo-section contains two parts; the upper part is the measured pseudo-section, and the lower part is the calculated pseudo-section (Fig. 5).

Figure 6 shows the inverted sections of resistivity data for the Ito campus.

\section{Discussion and conclusion}

The study area is located on the Ito Campus of Kyushu University (Fukuoka, Japan) and includes a flowing water spring named the Sayanokami spring. To determine the depth to the groundwater aquifer and its thickness, an electrical resistivity survey was conducted in February 2016 using a multi-channel CDMT system. The detected aquifer is located in sedimentary rocks (Table 1).

Groundwater contains various dissolved electrolytes, and it is ionically conductive, enabling electric current to flow into the ground. As a result, the availability of water can be determined by calculating the ground resistivity, taking into consideration the following properties:

1. Hard rocks with no pores or fractures, and dry sands devoid of water or clay, are extremely resistive, with resistivities of 10,000 to $50,000 \Omega \mathrm{m}$.

2. Porous fractured rocks containing free-flowing water have resistivities that depend on the water's resistivity and the rock's porosity, ranging from 20 to 4000 $\Omega \mathrm{m}$.

3. An impermeable clay layer containing bound water has low resistivity, ranging from 1 to $50 \Omega \mathrm{m}$.
4. Mineral ore bodies such as iron sulfides have very low resistivities because of their electric conductivity, usually lower or much lower than $1 \Omega \mathrm{m}$.

Both porous and non-porous rocks act as insulation until they are dry. Resistance decreases with increasing pore water content. Unconsolidated objects have higher resistance than compacted objects of the same composition (Saad et al. 2012). Sedimentary rock has good conductance and lower resistance than igneous rock. Clay has higher conductivity than sand because of the occurrence of iron clusters on the surface of clay particles. Based on our resistivity survey results, it is easy to distinguish between the major rock and water-bearing zones.

The inverted sections of Line 1 clearly show a relatively thin layer of low-resistance materials, identified as topsoil (about 1 to $8 \mathrm{~m}$ thick in Fig. 6a-d), with a resistivity between 30 and $50 \Omega \mathrm{m}$. This layer is probably a highly water-saturated and very conductive clay layer. Below this shallow layer, two different layers appear. The first layer has an electrical resistivity between 70 and $170 \Omega \mathrm{m}$ and represents the phreatic aquifer. The second layer is a resistive layer, with resistivities starting from around $300 \Omega \mathrm{m}$ and increasing with depth, and represents the bedrock.

For Line 2, the inversion results (Fig. 6e) show a relatively thin layer of highly resistive materials occurring as topsoil (about $2 \mathrm{~m}$ thickness) with a resistivity of more than $250 \Omega \mathrm{m}$. Below this layer, a conductive layer exists from 3 to $8 \mathrm{~m}$ with a resistivity of 16 to $50 \Omega \mathrm{m}$. Below this second layer, another layer is located at 8 to $18 \mathrm{~m}$ depth with resistivities between 50 and $150 \Omega \mathrm{m}$, representing the aquifer layer. Under this aquifer layer, there is a resistive layer with resistivities higher than $200 \Omega \mathrm{m}$ representing the bedrock layer.

For Line 3, the inversion results (Fig. 6f) show a shallow phreatic aquifer from 7 to $15 \mathrm{~m}$ depth with

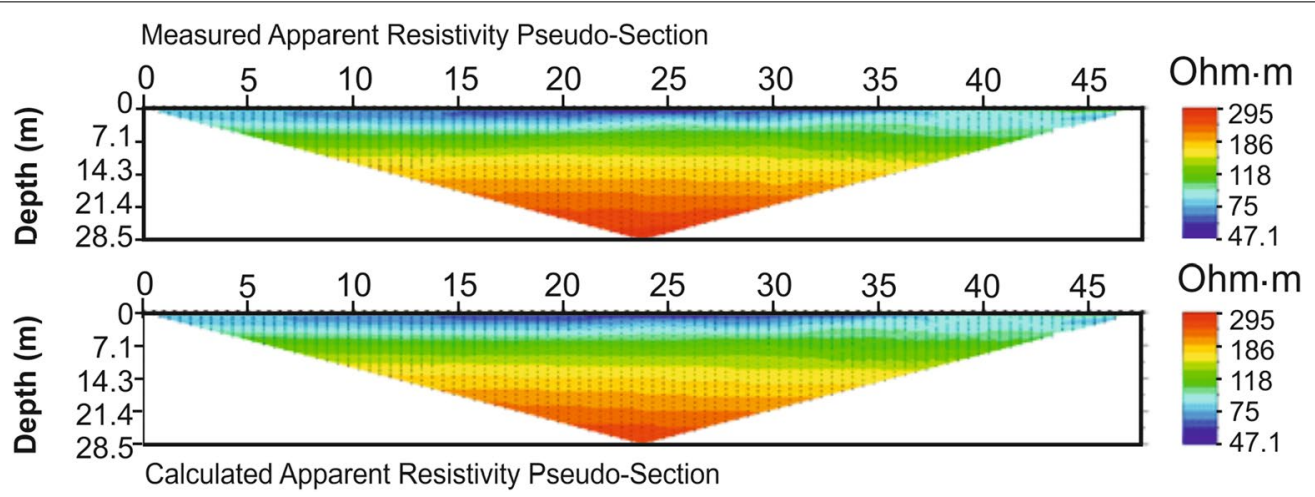

Fig. 5 An example of a pseudo-section of Line 3 


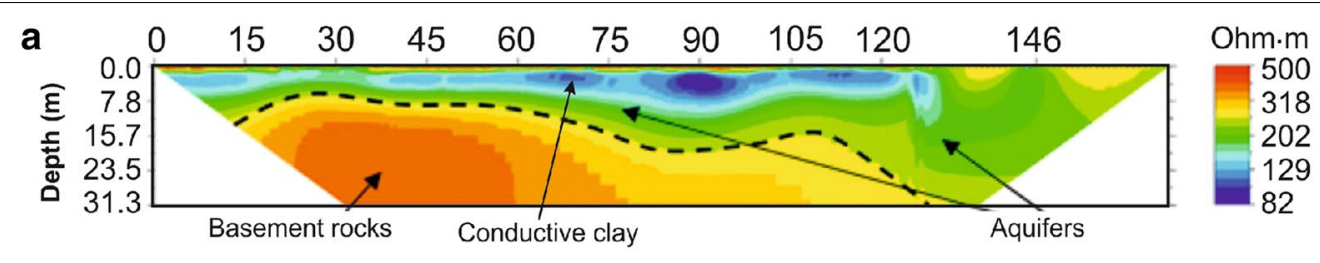

Iteration $=2, \mathrm{RMS}=5.95 \%, \mathrm{~L} 2=1.05$, Electrode Spacing $=0.5 \mathrm{~m}$

b
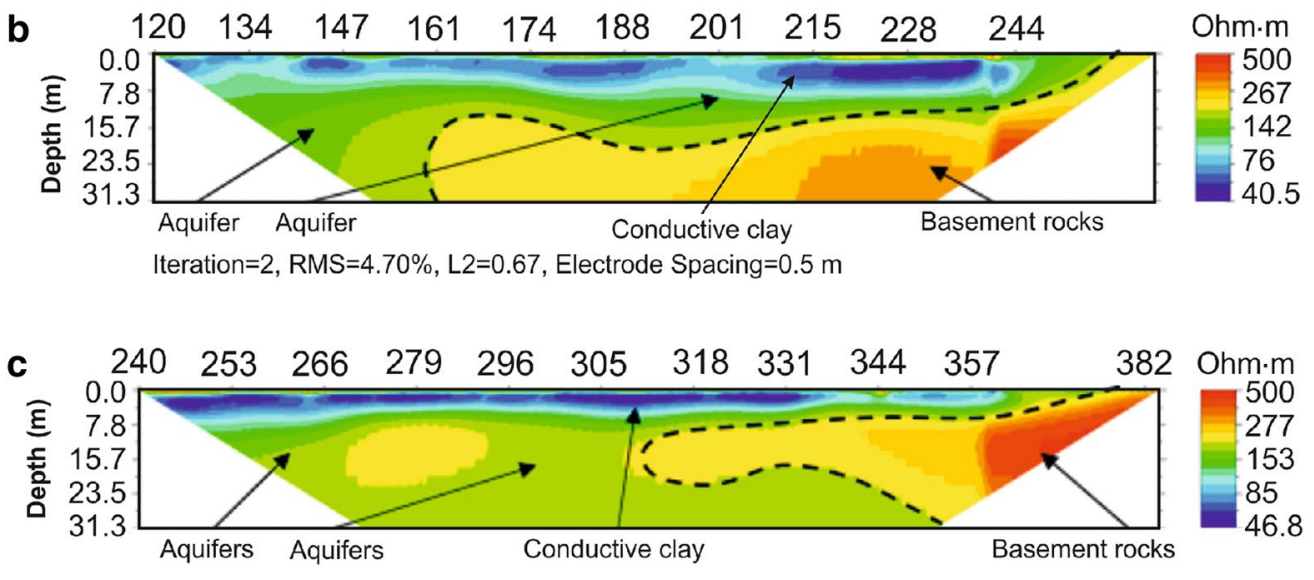

Iteration $=2, \mathrm{RMS}=4.70 \%, \mathrm{~L} 2=0.42$, Electrode Spacing $=0.5 \mathrm{~m}$

d
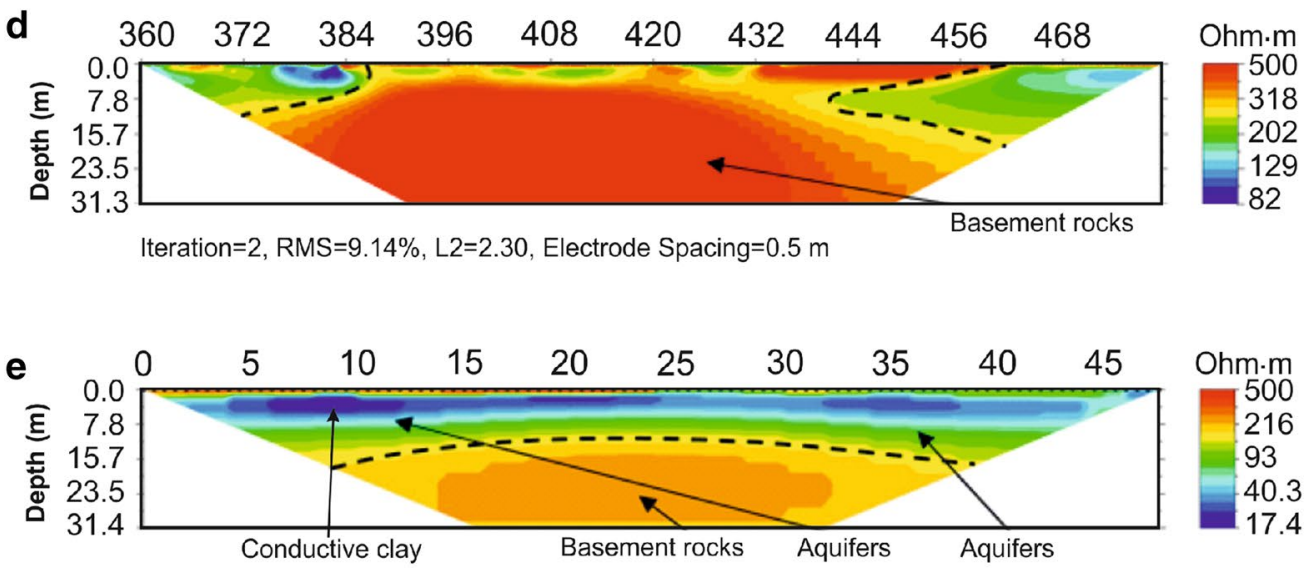

Iteration $=3, \mathrm{RMS}=6.11 \%, \mathrm{~L} 2=4.15$, Electrode Spacing $=0.5 \mathrm{~m}$

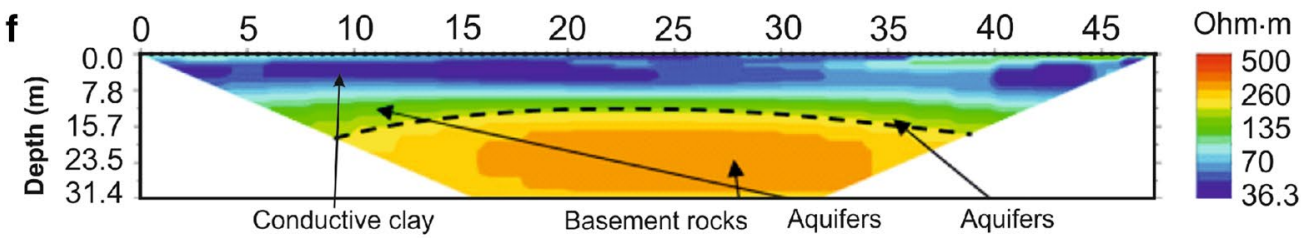

Iteration $=3, \mathrm{RMS}=4.80 \%, \mathrm{~L} 2=2.56$, Electrode Spacing $=0.5 \mathrm{~m}$

Fig. 6 a Inverted section of data from Line 1 section A (0-200 m); b inverted section of data from Line 1 section B (120-240 m); c inverted section of data from Line 1 section C (240-360 m); d inverted section of data from Line 1 section D (360-480 m); e inverted section of Line 2, and finverted section of Line 3 
Table 1 Resistivity of various types of water (Saad et al. 2012)

\begin{tabular}{ll}
\hline Type of water & Resistivity in $\Omega \mathrm{m}$ \\
\hline Meteoric water & $30-1000$ \\
Surface water in areas of sedimentary rock & $10-100$ \\
Groundwater in areas of igneous rock & $30-150$ \\
Seawater & $\approx 0.20$ \\
Groundwater in areas of sedimentary rock & $>1$
\end{tabular}

resistivities between 70 and $150 \Omega \mathrm{m}$, covered by a $10 \mathrm{~m}$ thick conductive layer. Below this aquifer layer, a resistive layer is located from $16 \mathrm{~m}$ depth to the bottom of the model. The resistivity of this resistive layer increases with depth and represents the bedrock.

In conclusion, the $2 \mathrm{D}$ inversion results from the pole-pole electrical resistivity array primarily delineated three electrical resistivity layers: (1) a shallow layer with low resistivity $(<50 \Omega \mathrm{m})$ interpreted as topsoil; (2) a groundwater aquifer $(50 \Omega \mathrm{m}$ to $170 \Omega \mathrm{m})$, and (3) a highly resistive bedrock ( $>200 \Omega \mathrm{m}$ ). These results are important for future groundwater exploration in the study area and can help in localizing drilling water wells in this area. Understanding the lateral extent of the shallow groundwater aquifer and the depth to the water-saturated zone (aquifer) will minimize the costs and time required for drilling. Such investigations are recommended for any hydrogeological characterization studies.

\section{Acknowledgements \\ S.W. acknowledges the financial support (master's degree scholarship) of the Japan International Cooperation Agency (JICA). The authors thank students of the Exploration Geophysics Laboratory (Kyushu University, Fukuoka, Japan) for help in the field. Figure 1 was created using the Generic Mapping Tools (Wessel and Smith, 1998).}

\section{Authors' contributions}

SW and HS performed the field survey. All authors contributed to the interpretation of the results and the preparation of the manuscript. All authors read and approved the final manuscript.

\section{Funding}

This research is supported by the Japan International Cooperation Agency (JICA).

\section{Availability of data and materials}

The data are available upon request to the authors.

\section{Declarations}

\section{Competing interests}

The authors declare that they have no competing interests.

\section{Author details}

1 Department of Earth Resources Engineering, Kyushu University, Fukuoka, Japan. ${ }^{2}$ Department of Geology, College of Science, United Arab Emirates University, P.O. Box 15551, Al Ain, UAE.
Received: 13 April 2020 Accepted: 7 April 2021

Published online: 14 April 2021

\section{References}

Archie GE (1942) The electrical resistivity log as an aid in determining some reservoir characteristics: Trans. AIME 146:54-62

Auken E, Christiansen AV (2004) Layered and laterally constrained 2D inversion of resistivity data. Geophysics 69(3):752-761. https://doi.org/10.1190/1. 1759461

CMT (2019): http://www.4d-geotek.com/botttom_Eservice.html. Accessed Mar 2019.

Constable SC, Parker RL, Constable CG (1987) Occam's inversion: a practical algorithm for generating smooth models from EM sounding data. Geophysics 52:289-300

De Clercq T, Jardani A, Fischer P, Thanberger L, Vu TM, Pitaval D, Côme J-M, Begassat $P$ (2020) The use of electrical resistivity tomograms as a parameterization for the hydraulic characterization of a contaminated aquifer. J Hydrol 587:124986. https://doi.org/10.1016/j.jhydrol.2020.124986

deGroot-Hedlin C, Constable S (1990) Occam's inversion to generate smooth, two-dimensional models magnetotelluric data. Geophysics 55:1613-1624

Dey A, Morrison HF (1979) Resistivity modeling for arbitrarily shaped twodimensional structures. Geophys Prospect 27(1):106-136

El-Qady G, Ushijima K (2001) Inversion of DC resistivity data using neural networks. Geophys Prospect 49:417-430

Galazoulas EC, Mertzanides YC, Petalas CP, Kargiotis EK (2015) Large scale electrical resistivity tomography survey correlated to hydrogeological data for mapping groundwater salinization: a case study from a multilayered Coastal Aquifer in Rhodope, Northeastern Greece. Environ Process 2:19-35. https://doi.org/10.1007/s40710-015-0061-y

Ghosh DI (1971) The application of linear filter theory to the direct interpretation of geoelectrical resistivity sounding measurements. Geophys Prospect 19:192-217

Greggio N, Giambastiani BMS, Balugani E, Amaini C, Antonellini M (2018) High-resolution electrical resistivity tomography (ERT) to characterize the spatial extension of freshwater lenses in a salinized coastal aquifer. Water 10(8):1067. https://doi.org/10.3390/w10081067

Griffith DH, Rooney WJ (1993) Two-dimensional resistivity imaging and modeling in areas of complex geology. J Appl Geophys 29:211-226

Kazakis N, Vargemezis G, Voudouris KS (2016) Estimation of hydraulic parameters in a complex porous aquifer system using geoelectrical methods. Sci Total Environ 550:742-750. https://doi.org/10.1016/j.scitotenv.2016. 01.133

Keller GV, Frischknecht FC (1996) Electrical methods in geophysical prospecting. Pergamon, London

Loke MH, Dahlin T, Rucker DF (2014) Recent developments of the direct-current geoelectrical imaging method. Geophysics 95:135-156

McNeill, J.D., 1990. Use of electromagnetic methods for groundwater studies. Geotechnical and Environmental Geophysics: Volume 1, Review and Tutorial. https://doi.org/https://doi.org/10.1190/1.9781560802785.ch7

Niculescu BM, Andrei G (2021) Application of electrical resistivity tomography for imaging seawater intrusion in a coastal aquifer. Acta Geophys. https:// doi.org/10.1007/s11600-020-00529-7

Rockhold ML, Robinson JL, Parajuli K, Song X, Zhang ZF, Johnson TC (2020) Groundwater characterization and monitoring at a complex industrial waste site using electrical resistivity imaging. Hydrogeol I 28:2115-2127. https://doi.org/10.1007/s10040-020-02167-1

Saad R, Nawawi MNM, Mohamad ET (2012) Groundwater detection in alluvium using 2-D electrical resistivity tomography (ERT). Electr J Geotech Eng 17:369-376

Sendros A, Himi M, Lovera R, Rivero L, Garcia-Artigas R, Urruela A, Casas A (2020) Electrical resistivity tomography monitoring of two managed aquifer recharge ponds in the alluvial aquifer of the Llobregat river (Barcelona, Spain). Near Surface Geophys 18(4):353-368. https://doi.org/10.1002/nsg. 12113

Telford WM, Geldart LP, Sheriff RE (1990) Applied Geophysics, 2nd edn. Cambridge University Press, Cambridge

Wessel P, Smith WHF (1998) New, improved version of generic mapping tools released. EOS Trans Am Geophys Un 79:579 
Yamaguchi, M., Shimoyama, S., Kameyama, T., Nishiyama, T., Tomita, S. (1984), Subsurface geological map of Maebaru, 1:50.000, National Land Agency of Japan.

\section{Publisher's Note}

Springer Nature remains neutral with regard to jurisdictional claims in published maps and institutional affiliations.
Submit your manuscript to a SpringerOpen ${ }^{\odot}$ journal and benefit from:

- Convenient online submission

- Rigorous peer review

- Open access: articles freely available online

- High visibility within the field

- Retaining the copyright to your article

Submit your next manuscript at $\boldsymbol{\nabla}$ springeropen.com 